\title{
Agile Leadership and Responsive Innovation in Initial Teacher Education: An Australian Case Study
}

\author{
Christopher Klopper, Donna Pendergast \\ Griffith University, Australia
}

\begin{abstract}
The case for agile leadership and responsive innovation in Australian Initial Teacher Education (ITE) through ensuing a three-stage process: reform, renew, and reflect was investigated in this case study. As such, the paper is organised under these three areas. Explicit links between the literature and the mandate for reform is presented. A case study approach then delineates the response to national and local imperatives framed as an opportunity for curriculum renewal. The case study presents the actions enacted to bring about innovative change. This investigation makes a significant contribution by accentuating the inhibitors and enablers encountered during a process of renewal and making a call for agile leadership and responsive innovation at this time of reform.
\end{abstract}

\section{Introduction}

Educational reform is a complex process. Underpinning most educational reform initiatives is ultimately the imperative to improve student-learning outcomes [8]. An analysis of twenty school education systems around the world [7] revealed there are eight predictable elements that contribute to effective reform. First, a system can make significant gains from wherever it starts... and it can achieve this in 6 years or less. Secondly, improving system performance ultimately is about improving the learning experience of students. There are typically three ways to achieve this goal - change structure by establishing new institutions, or decentralizing system responsibilities; change resources by adding more staff or by increasing system funding; and, change processes by modifying curriculum. All three of these intervention types - structure, resources, and process - are important along the improvement journey. Structure and resources are often the focus, whereas process should be the focus. Next, each particular stage of the system improvement journey is associated with a unique set of interventions, hence, it is important to learn from others at the same stage of the journey and to realise that doing more of the same will not propel a system to achieve different levels of improvement.
Fourth, different contexts respond to mandatory as opposed to persuasive arguments for reform. Hence, this is a decision that needs to be contextualised within the cultural and political context of the reform underway. Fifth, there are 6 'must haves' for reform

- Building the instructional skills of educators and management skills of leaders (efficacy)

- Assessing students

- Improving data systems (evidence)

- Improved education policy

- Revising standards and curriculum

- Ensuring appropriate rewards and remuneration for educators and leaders (esteem)

Next, systems further along the journey sustain improvement by balancing autonomy with consistent practice. Sustaining reform is achieved with collaborative practice the main mechanism both for improving teaching practice and building accountability.

Seventh, it is necessary to 'spark' reform. New conditions can ignite reforms and can stem from a socio-economic crisis; a critical report of system performance; or a change in leadership. And finally, leadership continuity is essential. Leadership is essential not only in sparking reform but in sustaining it. Two things stand out about the leaders of improving systems - their longevity: the median tenure of the new strategic leaders is six years; and improving systems actively cultivate the next generation of system leaders, ensuring a smooth transition of leadership and the longer-term continuity in reform goals.

Importantly, a 'spark' is often required to trigger major change and that a "system can make significant gains from wherever it starts and a timeline of 6 years or less is achievable" (p. 14)[7]. This spark can be the result of a crisis or a major reform initiative. This pattern is applicable to higher education reform, where opportunities also typically arise due to a 'spark' or initiative. What may at first glimpse appear to differ from reform in school settings and tertiary education settings are the time lines involved. However, closer scrutiny suggests 
that because of the length of the programs involved in tertiary education, the accreditation processes required, and the cultural shifts necessary to engage prospective students, the time commitment may well be very similar. We are interested to explore this facet of reform in tertiary education in this study.

\section{Reform}

In 2005, Pendergast and colleagues developed a model of key features and time involved in effecting major change in education settings, naming this the Educational Change Model (ECM). This was originally developed for reform processes in Australian middle schooling [9; 10]. More recently it has been used to facilitate state-wide reform of the early childhood sector in Victoria [6] and was the underpinning framework adopted for implementing Junior Secondary reform in Queensland across all government schools in Years 7, 8 and 9 [11]. Although the model was developed for a school education reform scenario, the underpinning principles are equally applicable to business, industry and community reform settings. Furthermore, the ECM has value for an individual, a site or setting, and at the systemic level. At the individual level it can be used to assist people to determine the stage of reform they are operating at by reflecting on their own understandings and practices and mapping this to predictable aspects of the reform stage. Similarly, in a specific site, the phase of reform can be determined by auditing the evidence presented across the site. At the systemic level the components of the phases outlined in the ECM support further progress in implementation. Hence, the adoption of the ECM is applicable to the innovative change in the wholeof-program reform charted in this case study.

The ECM proposes that programs of reform are typically established in three phases, gradually introducing particular core component changes, and typically spanning 6-7 years, depending upon contextual factors These phases are: the Initiation phase, the Development phase and the Consolidation phase. Both the ECM and the relevant literature recognise that educational reform often takes longer than expected or typically allowed for in reform schedules. The three broad phases can be mapped onto any major reform initiative, and feature indications of time taken to achieve each phase. The Initiation phase typically occupies the first year or two, the Development phase typically consumes the next two to five years, and the Consolidation phase can last over a further five to ten years. The time periods associated with each of the three phases are indicative only and can be accelerated through the alignment of contextual enablers. Concomitantly, inhibitors can lead to dips in the progress of the reform program, thus adding extra time to the overall reform process. Table 1 provides a summary of the core components of the ECM for each phase.

Table 1. Core Components of Educational Change Model

\begin{tabular}{|l|l|l|}
\hline \multicolumn{1}{|c|}{$\begin{array}{l}\text { Initiation Phase } \\
1-2 \text { years }\end{array}$} & $\begin{array}{c}\text { Development Phase } \\
2-5 \text { years }\end{array}$ & $\begin{array}{c}\text { Consolidation } \\
\text { Phase } \\
\text { 5-10 years }\end{array}$ \\
\hline - Introducing new & • Implement and & $\bullet$ Refine \\
language and & refine Quality & Quality \\
philosophy & Teaching model & Teaching \\
- Focus on & - Encourage emerging & practice \\
transition & leadership & Lead and \\
- Establish Quality & - Plan and implement, & support others \\
Teaching model - & revise and renew & Build \\
structures, & - Facilitate learning & capacity, \\
protocols \& & communities for & ownership \\
practices & teachers & and \\
- Establish & - Use and extend & sustainable \\
leadership model & evidence sources & practices \\
Plan and establish & •Develop support & \\
evidence & structures to enable & \\
principles & sustainability of & \\
- Develop & reform & \\
knowledge base & & \\
around initiative & & \\
&
\end{tabular}

Within the ECM, the role of the educator as an active agent of reform and development is crucial. University educators must be active and effective agents of the intended change. Providing opportunities for individuals to work together and have collective responsibility to improve practice is a positive, whereas a lack of agency has been recognised as a problem in program development. In order to achieve collaborative practices, educators need time to reach a common understanding and hence establish a shared commitment, thereby setting up the conditions for embedding a shift in the fabric of the teaching and learning [4]. The ECM has been adopted to underpin the overall approach to the implementation of reform in Initial Teacher Education (ITE) of interest in this paper.

A further feature of the ECM is recognition from the outset that there are predictable enablers and inhibitors to effective reform. Where the core components are not satisfactorily achieved within a particular phase there may be a dip in the pace and rate of progress of the reform. Enablers to reform include: clarity of vision and philosophy; existence of a risk taking culture; leadership at systemic, school and teacher levels of operation; encouraging a collaborative culture with an emphasis on teachers as members of a learning community; provision of support for teacher professional development; and resource commitment, including time and finances. Inhibitors to reform leading to downward dips in progress include: lack of leadership, lack of funding, lack of vision and philosophy, poor evidence base, and lack of commitment [9]. 
Hence, we are cognisant that the major change underway will typically traverse the phases of initiating, developing, and then consolidating the major reform. At the time of writing this paper we have journeyed through the initiation phase and in the next twelve months will move to the developing phase. The core components of the initiation phase include the establishment of a leadership model. This particular component is of particular interest in this paper. According to Taylor [13], leaders must be "agile decision makers, engage in critical selfreflection, integrate reflection with action, and collaborate with those who are diverse in considerable ways to be successful in a multifaceted global environment". In this context of our case study, Taylor's insights about agile leadership are of particular relevance. Five leadership factors around which agility contributed to curriculum reform were confirmed to be: technology adaptation, decisionmaking, teamwork, empowerment, and faculty collaboration. Later in this paper we return to the ECM as a lens to revisit the Initiation Phase, to consider the presence of agile leadership, and to reflect on the enablers and inhibitors.

\subsection{Reform in Australian Initial Teacher Education (ITE)}

In Australia, it is of considerable concern that school student learning outcomes are falling behind other countries, as evidenced by indicators such as the PISA and Tallis scores. The focus of the cause of this decline has landed squarely on teacher quality and is fueled by a lack of information about the impact of the variability in the quality of practice real or perceived - of initial teacher education programs around the nation. This focus is not new with a large number of reviews year after year giving voice to concerns by leading educators in the field about the importance of teacher effectiveness as one of the most important factors influencing school student learning outcomes [3,6]. Of these reviews, the latest which resulted in the publication of the report Action Now: Classroom Ready Teachers (Teacher Education Ministerial Advisory Group [14] sets out 39 recommendations to improve teacher readiness for classroom work. This review has had considerable impact around the nation, with all but one of the recommendations being accepted and funding for the implementation of the other recommendations being provided.

The TEMAG recommendations require significant change in ITE programs delivered by universities around Australia. Both Program Standards and student Graduate Standards must be demonstrated to be met through the delivery of the program. Notable among the changes is additional expectation related to:
- $\quad$ selection - to include non-academic as well as academic capabilities;

- evidence - of impact on student learning; and

- literacy and numeracy test - successful completion to meet the benchmark.

With regard to selection, the requirement is that a combination of both academic and non-academic capabilities be utilized. The academic component is relatively transparent and largely set according to institutional demand. However, the non-academic component is new as a requirement for entry. According to AITSL, the non-academic key capabilities associated with successful teaching identified in the research are: motivation to teach; strong interpersonal and communication skills; willingness to learn; resilience; self-efficacy; conscientiousness; organisational and planning skills [2]. Around the nation there are various responses to this requirement for all applicants, including: the use of standardised psychometric testing; or applicants participating in interviews; or other forms of written responses to prompts. In Queensland, in which our case study is located, a state-wide approach agreed to by all eleven universities has been negotiated. The benefit for students is they need complete only one form of non-academic capabilities entry test despite potentially applying at several universities. The approach also assures consistency, with the tool being administered and responses assessed independently by the Queensland Tertiary Admissions Centre (QTAC). The current information about the non-academic selection tool, also known as the NARTE (non-academic requirements for teacher education) is located publicly on the QTAC website and outlines the expectations and process for applicants to show their relevant work and life experiences that demonstrate the seven AITSL competencies and their understanding of and motivations about the course of study [12].

With respect to the evidence of having a positive impact on student learning, institutions are required to implement a Teaching Performance Assessment (TPA) which all students must successfully complete. Nationally, there are two consortia with multiple university members that are collaborating together to develop a TPA that will be administered in the final stages of the initial teacher education program and will serve as a hurdle to graduation. Not all universities belong to consortia and hence will develop their own instruments. The university in this case study is a member of a consortia currently working through the establishment of the comparability standards for the TPA that will be applied in thirteen universities around the nation.

The Literacy and Numeracy Test for Initial Teacher Education Students (LANTITE) is developed and delivered independently by the Australian Council for Educational Research (ACER). It is designed to assess initial teacher 
education students' personal literacy and numeracy skills and is designed to ensure teachers are well equipped to meet the demands of teaching and assist higher education providers, teacher employers and the general public to have increased confidence in the skills of graduating teachers. The LANTITE is delivered through an online assessment tool and all students enrolled in an initial teacher education course, both undergraduate or postgraduate, are expected to sit and pass the test prior to graduation [1].

Implementation of these reforms is actioned though increased demands for accreditation mandated by the Australian Institute for Teaching and School Leadership (AITSL) and implemented by state based authorities, in this case the Queensland College of Teachers (QCT). In this regard, the TEMAG agenda has provided a large 'spark' for program reform in ITE in Australia and all programs around Australia are required to meet these new national standards.

\section{National and local imperatives framed as an opportunity for curriculum renewal}

A case study of the Bachelor of Education is presented here to demonstrate the programmatic response to national and local imperatives framed as an opportunity for curriculum renewal. The case study highlights the inhibitors and enablers encountered during the renewal process, and presents the actions enacted to bring about the innovative renewal. Alongside this renewal process the university has been engaged in a broader renewal process which has been a further significant contextual factor enabling change.

\subsection{Griffith Model of Education}

In 2016, the key issues facing the University over the next decade formed the context for a further 'spark' for reform and provided opportunity for a wide-ranging dialogue with staff, including those delivering initial teacher education. In response, the Achieving Griffith 2020 Project was conceived and articulated to the Griffith university community. This strategy, which includes the Griffith Model of Education, seeks to position the University to respond to the challenges ahead and to ensure future growth. The Griffith Model of Education proposes strategies for enhancing the University's high performance culture and strongly positioning Griffith for the future. These proposals incorporate four key themes:

- Flexibility-focusing on student-centred flexibility, defined in terms of design, curricular and timetable responsiveness
- Quality_building on Griffith's excellent results for student satisfaction and evaluations of teaching by lifting quality more broadly across the institution (for example, increasing student progression, satisfaction, success and retention)

- Market-informed academic planningpromoting a carefully researched and analysed approach to academic innovation, taking into account student preferences, community needs and employer requirements

- Engaged and relevant - ensuring that Griffith graduates are prepared for the 'New World of Work'.

The key opportunity at this 'translation into practice' phase is progressively establishing 'ways of thinking and doing education' that will form the foundation for a 'new normal'. The corresponding risk, is engaging staff in a process of compliance, and thus while we are readily able to produce structural program changes (as evidenced by new degree structures and course profiles) the underlying educational processes (and the corresponding student experience) may remain largely untouched. To this end, the Bachelor of Education is a flexible yet focused degree for a complex profession.

A foundational assumption is that educators in all sectors share key values and knowledge that distinguish the teaching profession as one of the most critical occupations in contemporary society. This foundation is reflected in the design of the Bachelor of Education program. It introduces prospective teachers to core professional values and knowledge as a base on which to build rigorous, specialised knowledge equipping them to contribute to and lead education provision in primary and high schools. The degree is constructed in the belief that education and the teaching profession are historically, culturally and socially important endeavours that are undergoing continuous change as they respond to the demands of a busy, globalised, technological, competitive and often inequitable world. The program seeks to develop teachers who can contribute to this professional response in knowledgeable, critical, imaginative, and ethical ways. The principles of the Bachelor of Education degree are:

- Lifelong learning as a central concern for teachers and their students in a world that is producing knowledge and associated challenges at a rapid rate. Teachers need to equip learners for a life of effective learning. This learning is as much about maintaining what is valuable in the face of intense demands for change as it is about intelligently and humanely accommodating 
change. Teachers need to model this attitude to new knowledge whilst facilitating learning based on historical and contemporary knowledges that define our humanity and culture, and allow us to contribute productively to current demands of work, life and citizenship.

- Sensitivity to social justice and the role education and teachers can play in promoting it. Education is potentially a force for acknowledging and addressing social injustice in a world marked by great disparities between individuals and groups in terms of wealth, well-being and privilege. Teachers have a significant role in realising this potential of education through understanding diversity, critically reflecting on power and social structures, and imaginatively charting equitable pathways. Teachers can promote future social justice in the way they interact with others, in the messages they convey about diversity and justice, and in the interventions they make in the development of their students to redress, strengthen and infuse with hope and the knowledge and skills to promote justice.

- Leadership as a fundamental characteristic of teaching. Teachers lead learners to become aware, knowledgeable, humane contributors to society. Teachers can also lead in responding critically and ethically to demands on schools, taking a stand on the importance of the profession, the importance of education and the importance of good learning and teaching. Teachers lead positive workplace change by deep understanding of the project of education and the values of the teaching profession, and by sensitive understanding of the constant challenges that can undermine this project and these values. Teachers lead by imagining new pathways that preserve value by perceiving and judging opportunities and dangers. Teachers lead by modelling as well as by understanding and advocating.

- Understanding of the contexts and purposes of education that shape the day-to-day work and challenges of teaching. Education has been and continues to be shaped by powerful ideas, diverse knowledges, intense debates, and a sense of hope that change for the better is always possible. Teachers play a central role in realising the project of education, and do so in a way that comprehends the complex pressures on education, can critically assess competing demands, and can make ethical decisions that protect and promote the best interests of their students.
- Understanding of and commitment to contemporary standards of the teaching profession. Teachers are part of a professional community that is responsive to societal expectations and places stringent expectations on members of the community. The teaching profession produces and champions standards and values and the degree equips its preservice teachers to comprehend and adhere to professional standards. It also equips its graduates to play an active, imaginative and critical role in the continued development of the profession and ultimately in the refinement of its standards. The degree thus promotes engagement with current standards whilst developing a deeper understanding of the project of education and the nature of the teaching profession that will allow them to productively contribute to the ongoing development of the profession and its standards.

\subsection{Program renewal}

The Bachelor of Education is designed to connect professional knowledge, professional practice and professional engagement. Throughout the program the appropriate content, curriculum and pedagogical approaches are developed.

The program is a 320 credit point degree, completed in 3.5 calendar years. This new program has been developed in response to the two sparks of the TEMAG agenda and the Griffith Model of Education agenda.

In addition to the AITSL requirements, including the NARTE, LANTITE and TPA, ITE programs in Queensland, Australia have statutory pre-requisites required by the Queensland College of Teachers and implemented by legislation through accreditation of programs and hence eligibility of those graduating from the program for registration. Those entering Secondary teacher education programs must study Mathematics and English to Year 12 at a satisfactory standard, while those entering Primary programs must study Mathematics, English and Science. The design of the new Bachelor of Education program is that all students offered a place will have Mathematics and English as prerequisites. Students will be offered delayed choice in award major, in accordance with the Griffith Model of Education, and will decide at the end of Trimester 2 (T2) of First Year whether to enter the Primary or Secondary major. Students who select the Primary major who have not completed the Science pre-requisite will complete a bridging course during Trimester 3 (T3). 


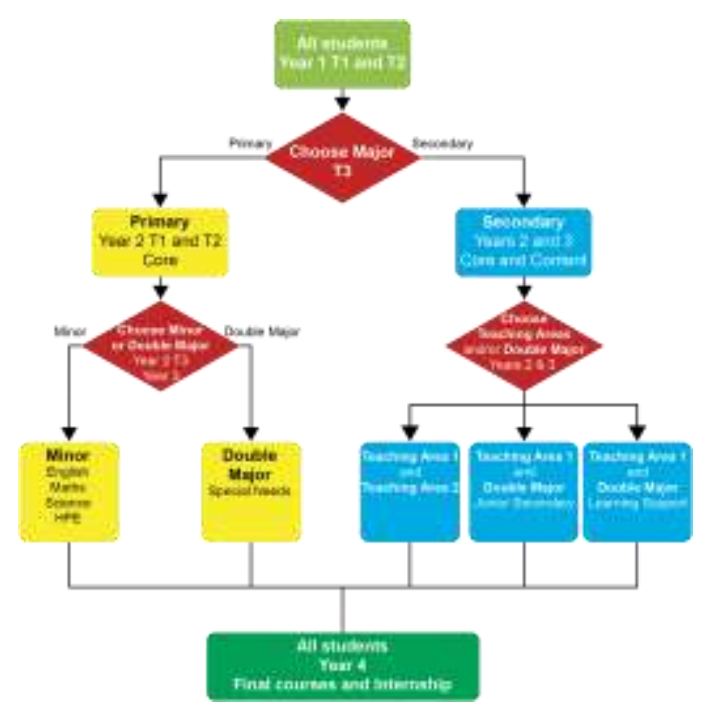

Figure 1. Bachelor of Education program structure

The Bachelor of Education involves students in an 80CP Foundation Year (T1 and T2). Students select a Major in either Primary or Secondary education at the end of T2 of first year and study appropriate courses in second and third years, culminating in $\mathrm{T} 1$ of Fourth Year which includes a capstone course. Students graduate mid-way through the Fourth Year with a Bachelor of Education, Primary Major OR a Bachelor of Education, Secondary Major.

Students participate in school-based Professional Experience (work integrated learning experiences) in all years of the program, concluding in an internship. Work integrated learning is a key part of the Bachelor of Education as a professional degree, and adding Professional Experience to all year levels of the program in both the Primary and Secondary Majors is one of the key motivations for the development of the new program. This is something strongly advocated by the School of Education and Professional Studies' Teacher Education Industry Advisory Groups (TEIAGs - representing principals, teachers and other professionals, meeting at each campus where teacher education courses are offered), as well as other principals and professional leaders who were consulted in the process of developing the program. Constraints imposed by the necessity of placing students in schools for their Professional Experience during the school year throughout the program mean that, although offering multiple entry points was carefully considered, all students will enter the program in Year $1 \mathrm{~T} 1$.

Trimesters 1 and 2 consist of 4 courses per trimester throughout the program, while fewer courses will be taught in Trimester 3 . This allows the $320 \mathrm{CP}$ program to be completed in 3.5 years. Students can then either enter employment or complete a Graduate Certificate to enhance their knowledge and skills at the completion of this degree. For example, students will have the option to complete Graduate Certificates in Early Childhood Education and Care, Teaching English to Speakers of Other Languages, Special Needs and Intervention Education or Autism Studies after their Bachelor of Education to deepen their skills in those areas before entering the classroom.

At the end of second year of the Primary Major students choose a Minor in English, Mathematics, Science or Health and Physical Education, or they choose a Double Major in Special Needs. (All students with the Primary Major complete either a Minor or the Double Major.) The structure of the program for Primary Major students is as follows:

- $\quad 80 \mathrm{CP}$ of Foundation courses (common first year),

- $\quad 200 \mathrm{CP}$ of Core courses (including 40CP of Professional Experience (work-integrated learning)) and 40CP of courses for a Minor teaching

area OR

- $180 \mathrm{CP}$ of Core courses (including 40CP of Professional Experience (work-integrated learning)) and 60CP of courses for the Double Major in Special Needs Education.

Students choosing the Secondary Major may choose two Teaching Areas, or may choose to select a single Teaching Area and a 60CP double Major in Learning Support, or a single Teaching Area and a 60CP double Major in Junior Secondary. The Junior Secondary Major focuses on either Maths/Science or English/Humanities and Social Sciences (HASS). The structure of the program for Secondary Major students is as follows:

- $\quad 80 \mathrm{CP}$ of Foundation courses (common first year),

- $80 \mathrm{CP}$ of Core courses,

- $120 \mathrm{CP}$ of content knowledge and pedagogical content knowledge courses in each of two Teaching Areas (60CP each) and

- 40CP of Professional Experience (workintegrated learning)

The program has been designed to ensure that each curriculum course addresses specific pedagogical approaches that incorporate the use of appropriate digital technologies. Additionally, a three-stage pedagogical plan that encompasses: leading towards, leading through and reflection, will guide the knowledge and understanding of preservice teachers in their capacities for demonstrating impact on their own student's learning. In all professional experience courses, pre-service teachers will adopt this pedagogical plan, with greater academic scaffolding and guidance in the earlier professional experience courses, so that pre-service teachers, by the end of the program have the 
knowledge and processes to articulate a planned pedagogical process for impacting on their student's learning. The three stages involve:

Leading towards: Prior to field placement a preservice teacher identifies a targeted practice (e.g. behaviour management or a curriculum domain). During lead-in days the pre-service teacher develops an understanding of the site class and the needs of the students. With the help of the class supervising teacher and through informed guidance and modelling from the course convenor, during campus contact, pre-service teachers make a plan for specific impact that works in unison with the curriculum plan. This plan includes approaches to data collection, evidence of student attainment and ongoing pedagogical evaluation.

Leading through: During the practicum the preservice teacher constructs daily conversations about student learning with peers, supervisors, university liaisons and teaching staff. Data is collected through student observations and documentations and through video snap-shots of pre-service teacher professional practice.

Reflecting: Pre-service teachers reflect in journal/blogs, participate in course discussion boards, give presentations periodically both at the school site and during on-campus tutorials, to illustrate learning. These will be utilised for formative group discussions on specific pedagogical strategies and plans. They will also provide contributing evidence to the pre-service teacher's ePortfolio.

The pedagogical process of leading towards, learning through and reflecting as integral components of each professional experience, provides pre-service teachers the opportunity to build the capabilities for making positive impacts on student learning as well as becoming a conscious and fundamental part of their craft. This enables students to obtain valuable opportunities to develop their knowledge, practice and engagement across the program against the Australian Professional Standards for Teachers - Graduate Level in an incremental and deepening manner. Students in the first year take courses that have a supportive and introductory focus, in relation to the professional standards. In the second year, students take courses that have a supportive, introductory and consolidated focus. In the third year, students enrol in courses that are mainly consolidated; while in their final year students undertake courses that require students to demonstrate Professional Knowledge, Practice and Engagements.

\section{Reflect}

Employing the Educational Change Model as the lens to frame the renewal process, the 6 core components of the Initiation Phase can be utilised as a reflection tool, following which comments about the enablers and inhibitors of this initiative can be considered. As outlined in Table 1, the Initiation Phase typically covers the duration of 1-2 years, following which the Developing Phase may range from 2-5 years, depending upon: the core components relevant to this phase; the effectiveness of the core components in the Initiation Phase; and the ongoing impact of enablers and inhibitors. The six core components of the Initiation Phase will now be utilized as a lens for reflecting on the initiative.

\subsection{Introducing new language and philosophy}

A range of new terms have been introduced that represent the notable shifts in the program. Of these the most significant is the use of the term 'foundation year' to describe a shared series of 8 courses that all ITE students in the program study prior to selecting their pathway as a primary or secondary teacher. Developing shared understandings of this terminology has been crucial for all stakeholders, including: academics delivering the program; school leaders; university committee members beyond the school; prospective students influencers for program choice, such as school principals, parents and friends. Methods of developing shared understandings have included the development of digital and paper based resources. Importantly, the: requirements of the NARTE; the LANTITE; and the TPA, have introduced a new set of acronyms with associated high stakes policy and procedures. These aspects are relevant nationally, providing a new common language across all ITE programs.

\subsection{Focus on transition}

This core component relates to attending to the many transition risks, such as the literal shift of students into the program, especially the first cohort; the transition of academics, especially with respect to adopting a new philosophical lens. A series of retreats with the academic team have assisted to develop shared understandings, to undertake transactional work such as developing weekly schedules, course profiles, and assessment pieces. This is a major change to previous models where courses have operated as insular, separated entities. 


\subsection{Establish Quality Teaching model - structures, protocols and practices}

Deepening quality-teaching practices affords the opportunity to explicitly articulate a set of strategies for success. The set of strategies are arrange around the following key areas: the teaching philosophy of the program, the student-centred approach to teaching, a deepening of the scholarship of learning and teaching in an ITE program, recognising innovations for development and employment, and identifying opportunities to demonstrate leadership.

\subsection{Establish the leadership model}

Clearly defining the leadership model for this program delivery was an early process in renewal in order to ensure both leadership and collaboration featured during this Initiation phase. Leadership via designated leaders has been explicit and in the collaborative retreats various leaders have emerged related to student wellbeing, assessment, administration, professional experience, alongside content area specialist teams. This has enabled a warp and weft model of leadership to emerge. Reflecting back to Taylor's [3] model of agile leadership, five core traits were identified as leading to positive curriculum reform in higher education technology adaptation, decision-making, teamwork, empowerment, and faculty collaboration. Each of these aspects were evident as the leadership model was adapted during the course of the initiation phase.

\subsection{Plan and establish evidence principles}

Formal quality indicators are mandated as part of any university program activity, especially those related to feedback from students. This program includes such evidence sources and in addition has adopted a series of research agendas, including: teacher efficacy, sense of belonging. This is combined with the additional requirements of the AITSL standards which demand that ITE students demonstrate the effect of their teaching on student learning outcomes.

\subsection{Develop knowledge base around initiative}

This final core component has been addressed by communicating frequently and fulsomely with all relevant stakeholders in their various contexts. The range of stakeholders is significant and diverse, including potential students, key influencers (such as parents), and members of the professional community who engage with the university for undertaking professional experience with students, accrediting authorities and other legislative jurisdictions. Within the university the knowledge base has also required considerable development as the additional features of the program, such as the requirements for the NARTE; the successful completion by students of the LANTITE and the TPA prior to graduation.

\subsection{Enablers and inhibitors of the reform initiative}

As the program continues to be delivered over time, the need for continued focus on reform remains paramount. As noted earlier in this paper, the ECM recognizes that it is typical for major reform to experience a dip when one or more of the enablers or inhibitors impacts on the reform process and this occurs across the three phases of initiation, development and consolidation, with each having various risks attached. For this initiative, there has been strong attention to the enablers of reform ensuring a clarity of vision and philosophy; existence of a risk taking culture; leadership at the relevant levels of operation; encouraging a collaborative culture with an emphasis on educators as members of a learning community; provision of support for relevant professional development; and resource commitment, including time and finances. In terms of resource allocation, several staff members were released from teaching and other responsibilities to focus on the development of the program and of the accreditation documents. A conservative estimate places this investment in excess of AUS\$200 000. Countering the enablers are the inhibitors to reform leading to downward dips in progress. The most notable of these - lack of leadership - was evident at times when the dual purposes of preparing accreditation materials whilst concurrently conceptualising and building the program pulled at the capacity to lead a range of teams to meet these various requirements. Upon reflection the divergent demands of leadership during this phase could have been better supported.

\section{Conclusion}

This case study delineates the response to national and local imperatives framed as an opportunity for curriculum renewal. It highlights the obligation for agile leadership and responsive innovation in Australian Initial Teacher Education (ITE) through ensuring a three-stage process: reform, renew, and reflect. The capacity for renewal is impacted by the enablers and constrained by the inhibitors. The journey of reform for this program is in its infancy, and a further 5-6 year commitment is required to see it through to a sustained model.

This program represents a major shift in the design of ITE programs which is evident through the reflective lens of the ECM. At this stage of the 
reform the Initiation Phase signified by six core components and consideration of the enablers and inhibitors reveals considerable investment into the reform. Importantly, it is essential to ensure the initiative moves through the Development Phase and then on to the Consolidation Phase, thereby achieving a sustainable model. The commitment of agile leadership and responsive innovation are key tools to enabling this reform goal.

\section{References}

[1] Australian Council for Educational Research (2017). Literacy and numeracy test for Australian students

[2] Australian Institute for Teaching and School Leadership (nd). Selection guidelines factsheet

[3] Dinham, S., and Rowe, K. Teaching and learning in middle schools: A review of the literature. ACER, Camberwell, Victoria, 2007.

[4] Fullan, M. Leading in a culture of change. Jossey-Bass, San Francisco, 2001.

[5] Garvis, S., Pendergast, D., Twigg, D., Fluckiger, B., Kanasa, H., Phillips, C., and Leach, D. The Victorian early years learning and development framework: Managing change in a complex environment. Australasian Journal of Early Childhood, Australian early Childhood Association, Melobourne, 38(2), 2013, pp. 86-94.

[6] Hattie, J. Teachers make a difference, what is the research evidence? Presented at the Australian Council for Educational Research Annual Conference, Melbourne, 1921 October 2003. http://research.acer.edu.au/research _conference_2003/4 (Access Date: 9 June, 2017).

https://teacheredtest.acer.edu.au/ (Access date: 4 September, 2017).

[7] Mourshed, M., Chijioke, C., and Barber, M. How the world's most improved school systems keep getting better, 2010, http://mckinseyonsociety.com/how-the-worlds-mostimproved-school-systems-keep-getting-better/ (Access Date: 9 June, 2017).

[8] Organisation for Economic Cooperation and Development (OECD). Education policy outlook: Making reforms happen. 2015, http://dx.doi.org/10.1787 19789264225442-en_(Access Date: 9 June, 2017).

[9] Pendergast, D. Fast-tracking middle schooling reform: A model for sustainability. Australian Journal of Middle Schooling, Trove, Toowong, 6(2), 2006, pp. 13-18.

[10] Pendergast, D., Flanagan, R., Land, R., Bahr, M., Mitchell, J., Weir, K., and Smith, J. Developing lifelong learners in the middle years of schooling. The University of Queensland, Brisbane, 2015.

[11] Pendergast, D., Main, K., Barton, G., Kanasa, H., Geelan, D. and Dowden, T. The education change model as a vehicle for reform: Shifting year 7 and implementing junior secondary in Queensland. Australian Journal of Middle Schooling, Trove, Toowong, 15(2), 2015, pp.5-19.

[12] Queensland Tertiary Admissions Centre (2017). Selection guidelines for initial teacher education courses http://www.qtac.edu.au/courses---institutions/teacher-entry (Access date: 4 September, 2017).

[13] Taylor, A. (2017). An examination of the relationships between agile leadership factors and curriculum reform in higher education. Unpublished Doctoral thesis.

[14] Teacher Education Ministerial Advisory Group (TEMAG). Action now: Classroom ready teachers, 2014, https://docs.education.gov.au/system/files/doc/other/15021 2_ag_response_-_final.pdf (Access Date: 9 June, 2017). 